\title{
Experimental Attempts to Reduce Predation by Harbor Seals on Out-Migrating Juvenile Salmonids
}

\author{
H. YURK* \\ Marine Mammal Research Unit, Fisheries Centre, University of British Columbia, \\ 6248 Biological Sciences Road, Vancouver, British Columbia, Canada V6T 1Z4, and \\ Vancouver Aquarium Marine Science Centre, \\ Post Office Box 3232, Vancouver, British Columbia, Canada V6B $3 \times 8$

\section{A. W. TRITES} \\ Marine Mammal Research Unit, Fisheries Centre, University of British Columbia, \\ 6248 Biological Sciences Road, Vancouver, British Columbia, Canada V6T 1Z4
}

\begin{abstract}
During spring, harbor seals Phoca vitulina feed at night under two bridges spanning the Puntledge River in Courtenay, British Columbia, Canada. Positioned parallel to one another, ventral side up, the seals form a feeding line across the river to intercept thousands of out-migrating salmonid smolts. During a 4week observation period in the spring of 1996, we attempted to disrupt the seals' feeding patterns by (a) deploying a mechanical feeding barrier (cork line), (b) altering the lighting conditions (lights on a bridge were turned off), and (c) installing an acoustic harassment device. We found acoustic harassment to be the most effective feeding deterrent. Of the other two deterrents, turning off the bridge lights was more effective than deploying a cork line, which had little effect. Acoustic harassment devices appear to be the most effective, nonlethal means for protecting juvenile salmonids from harbor seal predation in portions of the Puntledge River.
\end{abstract}

Natural predators that prey upon both out-migrating and returning anadromous fish can detrimentally affect the survival of depressed fish populations (Bigg et al. 1990; Fraker 1994; Olesiuk et al. 1995). In the northeast Pacific, seals and sea lions are commonly observed feeding on returning adult Pacific salmon Oncorhynchus spp. in rivers and estuaries during summer and fall (Spalding 1964; Olesiuk et al. 1990). Seals also intercept outmigrating smolts in spring and early summer (Olesiuk et al. 1995). Among the better-studied sealsalmon interactions are those in the Puntledge River on Vancouver Island, British Columbia (Bigg et al. 1990; Olesiuk et al. 1995; Trites et al. 1996; Figure 1).

Harbor seals Phoca vitulina in the Puntledge River regularly position themselves side by side, ventral side up, in the upstream shadow of two bridges near the light-shadow boundary. The seals

\footnotetext{
* Corresponding author: yurk@zoology.ubc.ca
}

Received November 29, 1999; accepted June 5, 2000 swim against the river current and hold their position in the water. Minimal movements of their hind flippers cause no apparent disturbance to the surface waters. This feeding strategy allows the seals to form an almost continuous barrier so they can intercept smolts that drift downstream near the surface. Apparently, the seals are assisted in their feeding efforts by the bridge lights that illuminate the water surface.

One way to enhance the survival of salmonids is to disrupt the feeding patterns of their predators. Techniques vary, but include making the smolts foul-tasting, creating a mechanical barrier that prevents seals from entering estuaries or river systems, and installing optic or acoustic harassment devices (AHD) to hinder the seals from feeding in particular areas (Gearin et al. 1986; Mate and Harvey 1987; Pfeifer 1989)

The AHDs are generally considered to be effective in deterring seals and sea lions from preying on fish in certain areas. The widespread use of these devices by aquaculture operators, who use them to deter seals and sea lions from entering netpens, attests to this claim. The AHDs have also deterred a large number of California sea lions Zalophus californianus from preying on returning winter steelhead Oncorhynchus mykiss in the Chittenden Locks, Seattle, Washington (Fox et al. 1996). However, at aquaculture sites and at the Chittenden Locks, some pinnipeds appear to become acclimated to AHD sounds and may have to be physically removed (Fox et al. 1996).

The goal of our study was to disrupt the feeding patterns of harbor seals feeding on smolts in the Puntledge River. During an observation period in April and May 1996, we evaluated three methods: installation of a mechanical feeding barrier, alteration of artificial light on the river, and deployment of an AHD. 


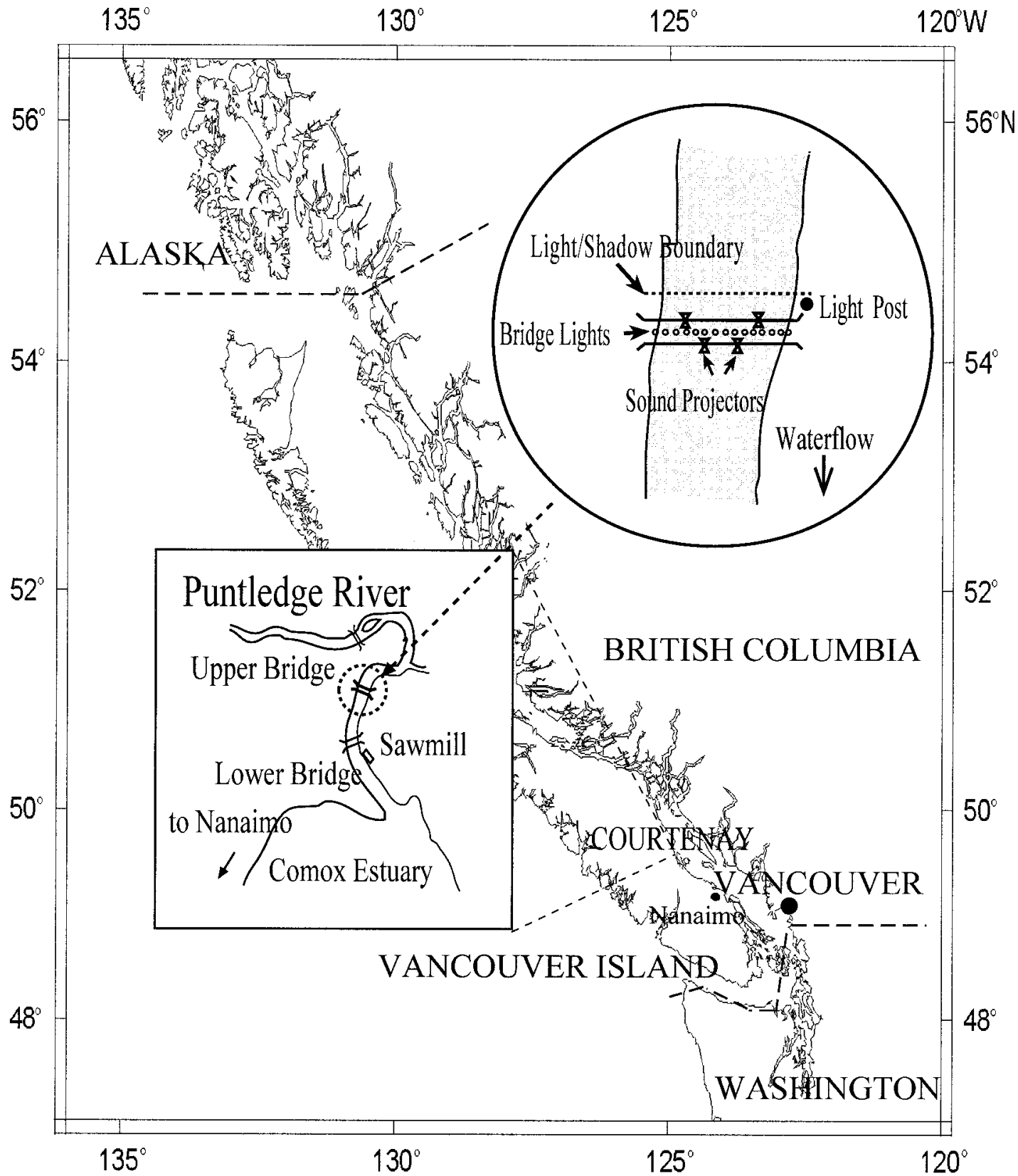

FIGURE 1.-Geographic area and detail map showing placement of sound projectors at the upper bridge on the Puntledge River, Courtenay, British Columbia.

\section{Study Site and Background}

The Puntledge River flows out of the north end of Comox Lake and continues through the city of Courtenay until it reaches Comox Harbor and the Strait of Georgia (Figure 1). Chinook salmon $O$. tshawytscha, pink salmon $O$. gorbuscha, coho salmon $O$. kisutch, and steelhead are raised at the
Puntledge River Hatchery and return to spawn in the Puntledge River system. The Puntledge River was historically one of the largest producers of chinook salmon in British Columbia. However, by 1995, only 208 chinook salmon returned to spawn (Trites at al. 1996).

Salmon smolts migrate out of the Puntledge Riv- 
er from March to May (C. Beggs, Puntledge River Hatchery, personal communication). Each year, the migration period begins with pink salmon smolts in March and April, followed by smolts of chum salmon O. keta during April and the first half of May. These are followed by coho salmon smolts at the beginning of May and chinook salmon smolts during the second half of May. The outmigrating smolts are of both wild and hatchery origin. The hatchery annually releases $3,000,000$ 6,000,000 chum salmon, 150,000-400,000 coho salmon, and around 1,000,000 pink salmon. However, in the year of our study (1996), pink salmon smolts were released directly into the estuary, thereby reducing the number of smolts in the river.

Approximately 200 harbor seals (increasing to 700 during the fall) haul out on $\log$ booms in the estuary of the Puntledge River year round (Bigg et al. 1990; Jurk et al. 1997; Figure 1). A considerably smaller number of harbor seals enter the river to feed on salmon smolts during the spring (Olesiuk et al. 1995). Visual scans of the river show that the seals feed in two primary areas: under the upper bridge (5th Street) and under the lower bridge (17th Street; Figure 1).

Seals entered the river at around dusk; the majority arrived later in the evening when a clearly defined light-shadow boundary formed under the two bridges (Olesiuk et al. 1995). Illumination of the water at the upper bridge was produced by 14 lights hanging over the center line of the bridge above the roadway (Figure 1). Depending on the height of the river, which was tidally influenced, the lights produced a relatively distinct, straight light-shadow line on the water surface 8-12 m both upstream and downstream of the upper bridge (Figure 1). The lower bridge did not have a row of center lights and, therefore, did not have a similar light-shadow boundary.

\section{Methods}

We tested three methods of seal deterrence to determine whether any prevented the seals from feeding at the upper bridge, their primary feeding site. The first treatment at the upper bridge involved the temporary installation of a mechanical feeding barrier. We strung a $60-\mathrm{m}$ rope that had cork floats spaced $1 \mathrm{~m}$ apart across the river beneath the bridge. Though we tried to place the rope along the shadow line, changes in tidal movements and river currents often caused it to move a few meters downstream (Figure 1). Therefore, we had to adjust the cork line several times during the experiment. For the second treatment, we extin- guished all of the upper bridge lights for four nights (Figure 1). For the third treatment, we used two different AHDs: (1) the "Seal-Scarer," produced by Airmar Technology (New Hampshire), which was used in seven of the eight experiments, and (2) the "MK3 Seal Scrammer," produced by Ferranti Thompson, Ltd. (Dorset, UK), which was only used once as we did not receive it in time to conduct a thorough test of its effectiveness.

The Airmar Seal-Scarer device consisted of a control unit and four sound projectors that were each attached by $30 \mathrm{~m}$ of cable. The AHD was configured to produce broadband signals that pitched at $27 \mathrm{kHz}$ and had a maximum source intensity at $10 \mathrm{kHz}$ (194 decibils [dB], referenced to $1 \mathrm{~Pa} / \mathrm{V}$ at $1 \mathrm{~m}$ from the sound source). The four sound projectors or transducers were suspended 40 $\mathrm{cm}$ below the water surface by ropes attached to floats. Attached to the bottom of each projector was a lead weight to ensure that the projectors remained upright and steady in the river current. The Airmar device was set to reach full intensity 1 min after being turned on. It then continuously alternated a 2-s sound burst through each of the transducers. The MK3 “Seal Scrammer” consisted of a control unit with one hydrophone-like transducer. It produced sounds ranging from 10 to 40 $\mathrm{kHz}$ and had a peak intensity at $27 \mathrm{kHz}(195 \mathrm{~dB})$.

The experiments were conducted by two observers in one 4-d period (two cork line treatments and two control nontreatments) and two 10-d periods (lights out, acoustic harassment, and control) during the nights of 22-26 April, 30 April-10 May, and 15-25 May 1996. We chose this study design after considering peak migration periods of smolts and the time that observers were available. Observations started each night at 2100 hours and ended at 0300 hours, for a total of $161 \mathrm{~h}$ of observation over $23 \mathrm{~d}$. Treatment (experiment) and nontreatment (control) nights were randomly selected throughout the observation period. The number of treatments during each observation period could not be kept constant because of a few nights of extreme rainy weather; bridge lights could not be turned off because of public safety concerns. In all, two experiments involved the mechanical feeding barrier (cork line), four experiments involved decreased illumination, and eight experiments involved an AHD. The total number of nontreatment (control) nights was nine.

The observers counted harbor seals every 30 min from the upper bridge decks with a red-filtered, $10^{6}$-candlepower spotlight to illuminate the river. Observers also counted seals at the lower 


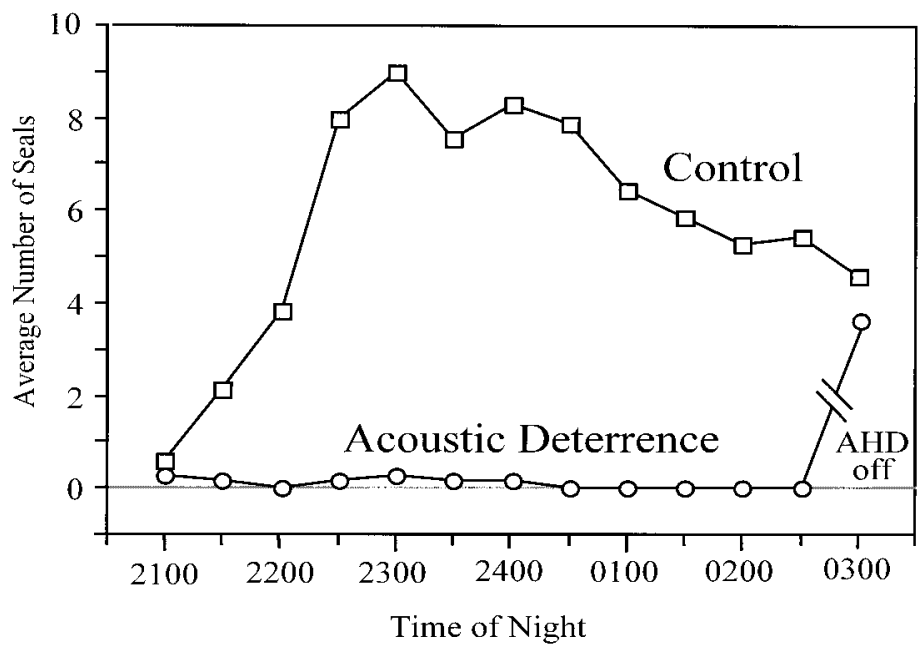

Figure 2.-Average number of seals present at the upper bridge on the Puntledge River, Courtenay, British Columbia, during count sessions on seven control nights and seven experimental nights when the Airmar acoustic harassment device was deployed. Note that the Airmar device was turned off at 0235 hours each experimental night.

bridge to determine whether the deterrents forced the animals to relocate. The maximum number of observations per night was 13 (Figure 2) at the upper bridge and 12 at the lower bridge. The seals were repeatedly counted by the two observers for a 5-min period; the highest number was retained as the best estimate of the number of animals present (counts by the two observers rarely differed). This procedure reduced the probability of underestimating the number of seals present.

We used a two-sample $t$-test to compare the mean number of seals present when the AHD device was deployed with the mean number present when no deterrent was used. The average number of seals present was calculated for each night of observation and treated as a single observation. Means of the nightly average number of seals were then calculated and compared for seven control nights and seven experimental nights.

\section{Results and Discussion}

On the control nights, when no deterrences were used, an average of 8 seals (range, 1-26) fed at the upper bridge. In contrast, we observed only 1 seal on average at the lower bridge (range, 0-8). During their nightly feeding routine, most seals appeared at the upper bridge $1.0-1.5 \mathrm{~h}$ after nightfall (between 2030 and 22:30 hours; Figure 2), and the majority appeared to stay until 0300 hours. The mean number of seals at the upper bridge rose from one at 2100 hours to nine at 2300 hours, dropping to an average of five by 0300 hours (Figure 2).
Seals started to appear downriver from the lower bridge earlier in the evening than at the upper bridge, but did not stay there long.

The presence of seals near the bridges did not always mean they were feeding. For example, a lack of head movement and absence of fish in the water column indicated that no feeding took place on the night of 23 April and that only sporadic feeding occurred on the night of 22 April. Feeding behavior also changed over the course of the study. From 24 April to 9 May, the seals stationed themselves at the water surface near the upstream shadow line and, with their ventral sides up, "gulped" the salmon fry (mainly chum salmon) that drifted downstream. After 15 May, the animals stayed further back in the bridge's shadow and more actively pursued their prey (mainly coho salmon smolts).

Olesiuk et al. (1995) estimated that harbor seals consumed an average of 140,000 chum salmon fry and 13,000 coho salmon smolts per night in 1994 . We did not remeasure the feeding rates because we were concerned that illuminating the animals with a red spotlight for long stretches of time might affect their behavior and confound our experiment. In contrast to Olesiuk et al. (1995), we observed a behavioral response to the red light: the seals often moved away and seemed sensitive near the light-shadow line of the spotlight. Our procedure of continuous counts during a 5-min period paid special attention to the possibility of animals avoiding the spotlight.

Tidal heights and freshwater flow influenced 
Experiments: $\mathrm{K}=$ Corkline; $\mathrm{L}=$ Lights out; $\mathrm{A}=\mathrm{AHD} \# 1 ; \mathrm{F}=\mathrm{AHD} \# 2 ; \mathrm{C}=$ Control

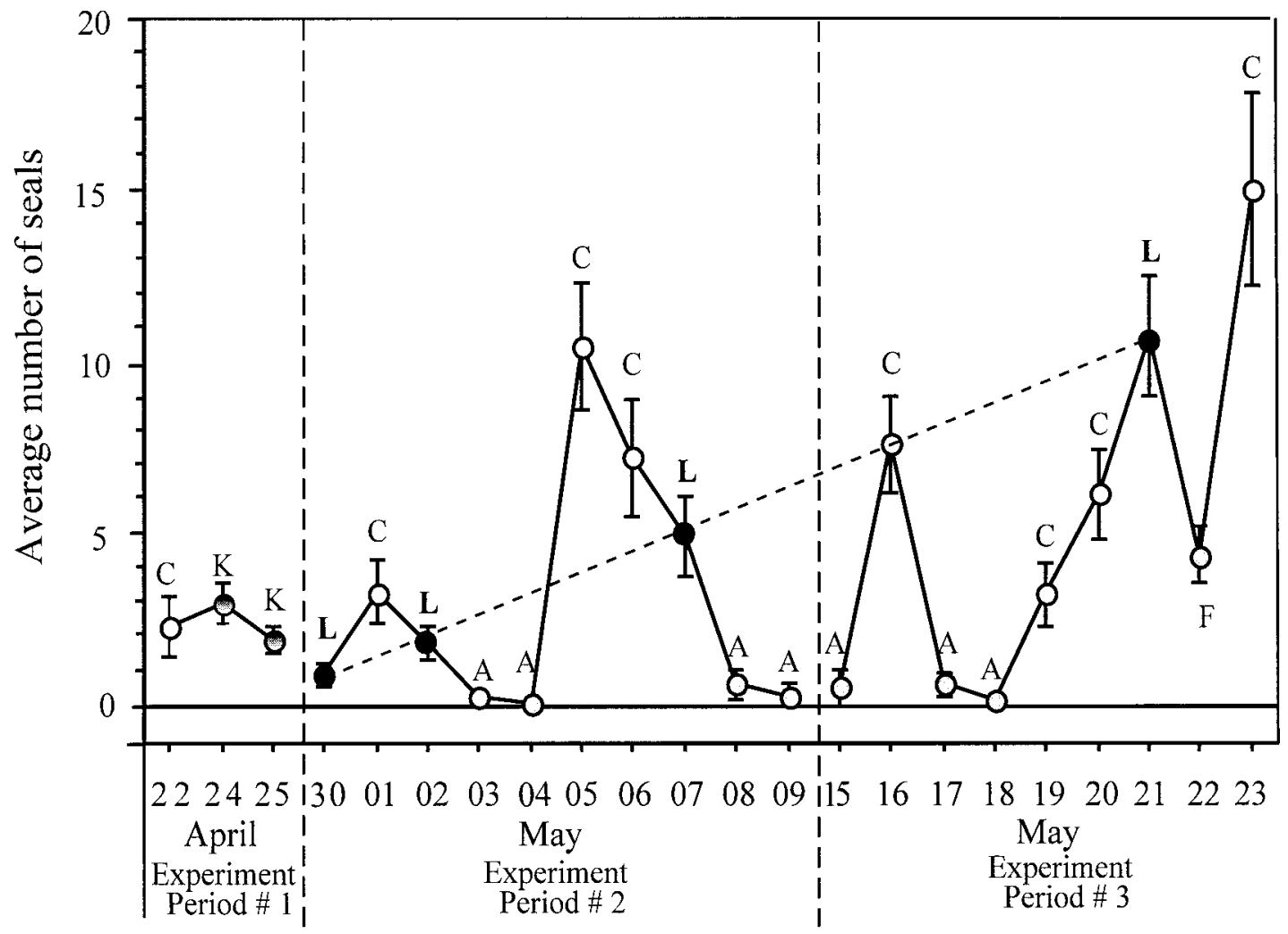

Figure 3.-Average number of seals present at the upper bridge on the Puntledge River, Courtenay, British Columbia, on each observation night. Seals were counted every $30 \mathrm{~min}$, for a total number of 13 counts/night (bars $= \pm \mathrm{SE})$. Letter symbols indicate the type of treatment applied.

feeding activities at the upper bridge. During extreme low tides, the water depth was below $1.5 \mathrm{~m}$. Our observations found that the seals did not attempt to feed until the tide raised the river to almost $2 \mathrm{~m}$. Tidal heights were estimated by comparing hydrographic charts of the river with tidal heights published in regional tide tables. However, our estimates neither took into account the amount of runoff from the lake nor the effects of variable rainfall. During the first 2 weeks of observations in 1996, rainfall exceeded the annual average and caused the Puntledge River to flow faster and at a higher level than normal. This seemed to affect feeding; we did not observe seals feeding on nights of extreme rainfall.

Spot checks along the river away from the bridges revealed a number of seals feeding in areas illuminated by other light sources. For example, we observed as many as seven seals feeding in a stretch of river that was lit by halogen lights from a ballpark at Lewis Park (upstream of upper bridge). In addition, halogen lights used by a sawmill (below the lower bridge) illuminated another area frequented by feeding seals.

\section{Treatment 1: Cork Line}

At the upper bridge, we deployed the cork line on two nights for an average of $3 \mathrm{~h}$ each night (Figure 3 ). Within $1 \mathrm{~h}$ of setting the cork line on the first night, the number of seals feeding at the lower bridge increased from one to four. As the night progressed, the number of seals at the lower bridge steadily dropped and more seals began appearing next to the cork line at the upper bridge. On the following night, we deployed and retrieved the cork line twice. The animals were not at either bridge during the first deployment and did not seem to be disturbed by the second deployment. A drop in the number of seals toward the end of the second deployment suggested a mild response 
TABLE 1.-Number of harbor seals counted at the upper bridge on 7 control nights and 7 nights when the acoustic harassment device (AHD) was deployed. The means (standard deviations) for the control and AHD nights were 7.57 (2.96) and $0.36(0.20)$, respectively.

\begin{tabular}{crc}
\hline Night & Control & AHD \\
\hline 1 & 3.31 & 0.23 \\
2 & 10.46 & 0.08 \\
3 & 7.23 & 0.62 \\
4 & 7.62 & 0.31 \\
5 & 3.23 & 0.54 \\
6 & 6.15 & 0.62 \\
7 & 15.00 & 0.15 \\
\hline
\end{tabular}

to the deterrent. However, the seals that remained appeared to engage in some form of play with the cork line. We concluded that though the cork line had a short-term initial effect on the seals, the animals were quick to habituate to it. We did not attempt any further trials with the cork line after these two nights of testing.

\section{Treatment 2: Lights Out}

Fewer seals were observed feeding the first night we turned off the lights at the upper bridge compared with adjacent control nights when the lights were left on (Figure 3). However, on subsequent experimental nights, we noted a progressive increase in the number of seals feeding in the residual light (closed circles in Figure $3 ; F_{1,3}=17.5$, $P=0.05)$. By the end of four experimental nights, numbers appeared to reach and even exceed those observed during comparable control nights (Figure $3)$. Although we do not know whether the reduced light affected their feeding efficiency, the results of this experiment suggest that the seals learned to compensate for the reduced lighting by making effective use of the residual city lighting. Therefore, we concluded that, though the "lights-out" treatment was initially effective as a deterrent, the seals eventually habituated to the lighting change.

\section{Treatment 3: Acoustical Deterrence}

Significantly fewer seals fed at the upper bridge on the seven nights we deployed the Airmar device compared with seven control nights when no deterrent was used $\left(t_{12}=4.60, P=0.001\right.$; Figures 2, 3; Table 1). A mean of 0.4 animals was present during the acoustical tests (range, 0-1) compared with a mean of 8 animals on control nights (range, 0-26). On most experimental nights, no seals fed within a 50-m radius of the bridge.

The first two nights we deployed the Airmar device at the upper bridge, significantly more seals appeared at the lower bridge than were previously counted on control nights and during the lightsout experiment. On subsequent experimental nights, the numbers dropped steadily at the lower bridge until no seals were observed feeding there. We presume this drop in numbers at the lower bridge reflected poor feeding conditions at this location.

\section{Conclusions}

Our results show that AHDs were the most effective of the three methods tested to deter seals from feeding on salmon smolts in the Puntledge River. Extinguishing the bridge lights was the second most effective deterrent, followed by the cork line, which had little, if any, effect. The upper bridge appeared to be the preferred feeding site for the harbor seals, as lighting and river topography at this bridge are probably ideal for optimal foraging success. Given that it is doubtful that all incandescent light sources around this bridge can be extinguished, acoustic deterrence could be used to control predation during the months of April and May.

The AHDs are effective within a limited range, but cannot prevent seals from entering the river or from moving or feeding in other areas of the river. The seals only have to swim with their heads out of the water to avoid the underwater noise. By installing AHDs at the Chittenden Locks in Seattle, Washington, the number of sea lions feeding on returning steelhead decreased over the course of 2 years (Fox et al. 1996). Similarly, AHDs could be effective for deterring seals in the Puntledge River and other salmon-producing streams until better measures to protect salmonids are implemented. However, acoustic deterrence can probably only be used as a temporary predation-control mechanism because pinnipeds have a strong ability to learn and adapt to sounds (Fraker 1994). For example, changes in the abundance and availability of prey may lead to motivational changes in pinniped behavior (from avoiding AHDs to ignoring them). Therefore, the effectiveness of the AHDs in the Puntledge River should be tested again during spring out-migrations and, possibly, during fall returns. Hopefully, the Department of Fisheries and Oceans, which is responsible for protecting salmon and seals in Canada, will undertake the necessary steps to continue testing the effectiveness of AHDs.

\section{Acknowledgments}

We thank our field assistant, Christy Wilson, for the many hours she spent in darkness and pouring 
rain watching and counting seals. Also, we are grateful to Graeme Ellis and George Horonowitsch of the Pacific Biological Station, Department of Fisheries and Oceans (DFO), for their relentless efforts to provide the necessary equipment and logistics to plan and execute this study. We would also like to thank Steven Christensen from Airmar Technology, Ltd., and John Ace-Hopkins from Ferranti-Thompson, Ltd., for lending us their AHDs; and Harry Genoe, Chris Beggs, and the staff of the Puntledge River Hatchery for providing boats, technical assistance, and manpower during the study, as well as the City of Courtenay for helping us turn on and off the bridge lights. Furthermore, we would like to thank the Institute of Ocean Sciences, DFO, for providing hydrographic charts of the river. We also thank John Ford for his advice on the design of the study and for allowing us to use his laboratory at the Vancouver Aquarium Marine Science Centre to analyze data. A.W.T. was supported in part by the North Pacific Marine Science Foundation through the North Pacific Universities Marine Mammal Research Consortium. Finally, we would like to thank Jim Boutillier and the Department of Fisheries and Oceans for providing the funds to conduct this study, and Lance Barrett-Lennard, David Rosen, Bruce Wright, and two anonymous reviewers for their comments on earlier drafts of this manuscript.

\section{References}

Bigg, M. A., G. M. Ellis, P. Cottrell, and L. Milette. 1990. Predation by harbour seals and sea lions on adult salmon in Comox Harbour and Cowichan Bay, British Columbia, Canada. Technical Report of Fisheries and Aquatic Sciences 1769.

Fox, W. W., B. Delong, P. Dygert, S. Foley, P. Gearin, S. Jeffries, B. Norberg, and J. Scordino. 1996. Environmental assessment on conditions for lethal removal of California sea lions at the Ballard Locks to protect winter steelhead (Supplement). NOAA, NMFS, Washington, D.C.

Fraker, M. A. 1994. California sea lions and steelhead trout at the Chittenden Locks, Seattle, Washington. Report to Marine Mammal Commission, Washington, D.C.

Gearin, P. J., R. Pfeiffer, and S. J. Jeffries. 1986. Control of California sea lion predation of winter-run steelhead at the Hiram M. Chittenden Locks, Seattle, December 1985-April 1986. Washington Department of Wildlife, Fishery Management Report 8620, Mill Creek.

Jurk, H., A. W. Trites, C. L. Wilson, G. M. Ellis, and J. K. B. Ford. 1997. Reducing predation of salmonids caused by harbour seals (Phoca vitulina) in the Puntledge River. Part 2: adult summer chinook-June and July 1996. Report to University of British Columbia, Department of Fisheries and Oceans, Pacific Region, Ottawa.

Mate, B., and J. Harvey, editors. 1987. Acoustical deterrents in marine mammal conflicts with fisheries. Report on a workshop held in February 1986 in Newport, Oregon. Oregon State University, Sea Grant College Publication ORESU-86-001, Portland.

Olesiuk, P. F., M. A. Bigg, G. M. Ellis, S. J. Crockford, and R. J. Wigen. 1990. An assessment of the feeding habits of harbour seals (Phoca vitulina) in the Strait of Georgia, British Columbia, based on scat analysis. Canadian Technical Report of Fisheries and Aquatic Sciences1730.

Olesiuk, P. F., G. Horonowitsch, G. M. Ellis, T. G. Smith, L. Flostrand, and S. C. Warby. 1995. An assessment of harbour seal (Phoca vitulina) predation on outmigrating chum fry (Oncorhynchus keta) and coho smolts $(O$. kisutch) in the lower Puntledge River, British Columbia. Canadian Department of Fisheries and Oceans, Pacific Region, PSARC Document, Nanaimo.

Pfeifer, B. 1989. Monitoring of 1988-1989 California sea lion control program in the Lake Washington estuary. Washington Department of Wildlife, Fishery Management Report 90-17, Mill Creek.

Spalding, D. J. 1964. Comparative feeding habits of the fur seal, sea lion and harbour seal on the British Columbia coast. Fisheries Resource Board of Canada Bulletin 146.

Trites, A. W., C. W. Beggs, and B. Riddell. 1996. Status review of the Puntledge River summer chinook. Department of Fisheries and Oceans, Pacific Region, PSARC Document S96-16, Namaino. 